\title{
Bi-Material Micro-Part of Stainless Steel and Zirconia by Two-Component Micro-Powder Injection Molding: Rheological Properties and Solvent Debinding Behavior
}

\author{
Al Basir, Abu Bakar Sulong *, Nashrah Hani Jamadon and Norhamidi Muhamad \\ Department of Mechanical and Manufacturing Engineering, Faculty of Engineering and Built Environment, \\ Universiti Kebangsaan Malaysia, 43600 Bangi, Selangor, Malaysia; al.basir005@yahoo.com (A.B.); \\ nashrahhani@ukm.edu.my (N.H.J.); norhamidi@ukm.edu.my (N.M.) \\ * Correspondence: abubakar@ukm.edu.my; Tel.: +60-3-8921-6678; Fax: +60-3-8925-9659
}

Received: 16 March 2020; Accepted: 1 April 2020; Published: 2 May 2020

\begin{abstract}
From the micro-powder injection molding ( $\mu \mathrm{PIM}$ ) process, a two-component micro-powder injection molding (2C- $\mu$ PIM) process has evolved due to the growing demand for multi-functional micro-components in avant-garde applications. $2 \mathrm{C}-\mu \mathrm{PIM}$ technology provides the opportunity to conjugate distinct materials within one part. Stainless steel (SS 17-4PH) and $3 \mathrm{~mol} \%$ yttria-stabilized zirconia (3YSZ) are characteristically recognized for their corrosion resistance and high hardness. In this work, the obtained critical powder volume concentration (CPVC) of SS 17-4PH and 3YSZ powders were 71.7 and $47.1 \mathrm{vol} . \%$, respectively. Solid loadings of 2 and 3 vol.\% less than the CPVC were considered as the optimal content for both powders. Feedstocks were obtained by mixing SS 17-4PH and 3YSZ powders with a binder system comprised of palm stearin (PS) and low-density polyethylene (LDPE). The rheological behaviors of the prepared feedstocks were assessed to figure out the feedstocks having the best rheological properties. The feedstocks of SS 17-4PH and 3YSZ with powder loadings of 69 and 44 vol.\% were eventually injected to produce bi-material micro-parts. The optimal solvent debinding temperature of the green bi-material micro-part was then investigated, and it was found that $73.3 \%$ soluble binder was removed when bi-material was immersed in acetone at $70{ }^{\circ} \mathrm{C}$ for $40 \mathrm{~min}$.
\end{abstract}

Keywords: powder injection molding; bi-material micro-part; feedstock; rheological properties; debinding

\section{Introduction}

The global trend towards the miniaturization of products and the necessity of incorporating different functional capabilities within one micro-component have played a significant role towards the evolvement of the two-component micro-powder injection molding ( $2 \mathrm{C}-\mu \mathrm{PIM})$ process from previous micro-powder injection molding $(\mu \mathrm{PIM})$. The significant use of material and low production costs has also contributed towards $2 \mathrm{C}-\mu \mathrm{PIM}$ as a commendable manufacturing technique in which two dissimilar materials can be joined, thereby producing a smooth gradient interface using a similar injection molding machine [1,2]. In this study, the selected materials are stainless steel (SS 17-4PH) and $3 \mathrm{~mol} . \%$ yttria-stabilized zirconia (3YSZ). The joining of metal and ceramic is considered to be an excellent option for applications in several engineering fields and industries. This is because ceramics not only display high resistance to corrosion and wear but they also exhibit persistent mechanical and thermal properties at elevated temperatures, whereas metals are ductile with excellent thermal and electrical conductivity. The implementation of the $2 \mathrm{C}-\mu \mathrm{PIM}$ process is first initiated with the mixing of 
metal and ceramic powders individually with the multi-component binder system in order to prepare homogeneous feedstocks. The rheological measurements are then performed on the feedstocks, which is important to obtain successful injection molded parts. Simultaneous or sequential mechanism are usually employed to produce green bi-material micro-parts by feeding each type of feedstock as a granulated form into the same injection molding machine. Following the injection molding process, demolding is performed, which is the expulsion of the green part from the mold cavity. The soluble and insoluble binders of the green bi-material micro-structured part are eliminated by the solvent and thermal debinding technique, respectively. Lastly, the debound part is sintered to achieve the obligated physical and mechanical properties.

The binder system plays a very important role in the powder injection molding process since the quality of the final product is substantially influenced by this $[3,4]$. Therefore, proper selection of appropriate binders is required. The important qualities of good binders include excellent flow behavior, favorable interaction with powder, excellent binder extraction characteristics, non-toxic and low-cost [5,6]. In this study, a binder system composed of palm stearin (PS) and low-density polyethylene (LDPE) was utilized where PS and LDPE functioned as primary and secondary or backbone binders, respectively. The reason behind selecting PS in this study is because of its quality of dual functionality since it works as surfactant and lubricant at the same time [7]. The literature also supports the use of PS binders in the field of powder injection molding $[8,9]$.

The process of binder elimination is sensitive; if a delicate process in powder injection molding is not given, there is the distinct possibility of formation of defects or cracks occurring during the process $[10,11]$. The key objective of the debinding process is to eliminate the soluble and insoluble binders from the green compact within the least time without producing any severe impact on it. The debinding method that is mostly employed by researchers is the combination solvent and thermal debinding process [12,13], as this approach reduces the total time required for debinding the sample. To perform the solvent debinding process, the green part is first immersed in the solvent at a certain temperature. It has been shown that heptane, hexane, acetone, and ethanol are used as a solvent in different research studies [14]. In this study, acetone is applied as a solvent. During the solvent extraction process, an open pore structure is formed, which not only expedites the elimination of the insoluble binder during the thermal extraction process but also significantly reduces the time required for thermal extraction [15].

This study aimed to perform the rheological analysis of the SS 17-4PH and 3YSZ feedstocks in order to conduct an excellent molding operation to prepare the green bi-material micro-parts of SS 17-4PH and 3YSZ. An investigation was also carried out to determine the optimal solvent debinding temperature for the green bi-material micro-parts.

\section{Experimental}

\subsection{Materials}

The materials used in this study were SS 17-4PH (Sandvik Materials Technology, Sandviken, Sweden) and 3YSZ powder (Inframat Advanced Materials LLC, Manchester, CT, USA) (Figure 1a,b), and had a $D_{50}$ of $7.5 \mu \mathrm{m}$ and $172.4 \mathrm{~nm}$, respectively (Figure $2 \mathrm{a}, \mathrm{b}$ ). Helium gas pycnometer was used to determine the pycnometer densities, and the obtained values for SS 17-4PH and 3YSZ were 7.7435 and $5.6387 \mathrm{~g} / \mathrm{cm}^{3}$, respectively. The binder system designed for this experiment consisted of palm stearin (PS) and low-density polyethylene (LDPE). PS as a primary binder was employed to improve the rheological properties and wettability, whereas LDPE as a backbone polymer was used to retain the shape of the component after injection molding and debinding [16]. The characteristics of the binder components are shown in Table 1. 

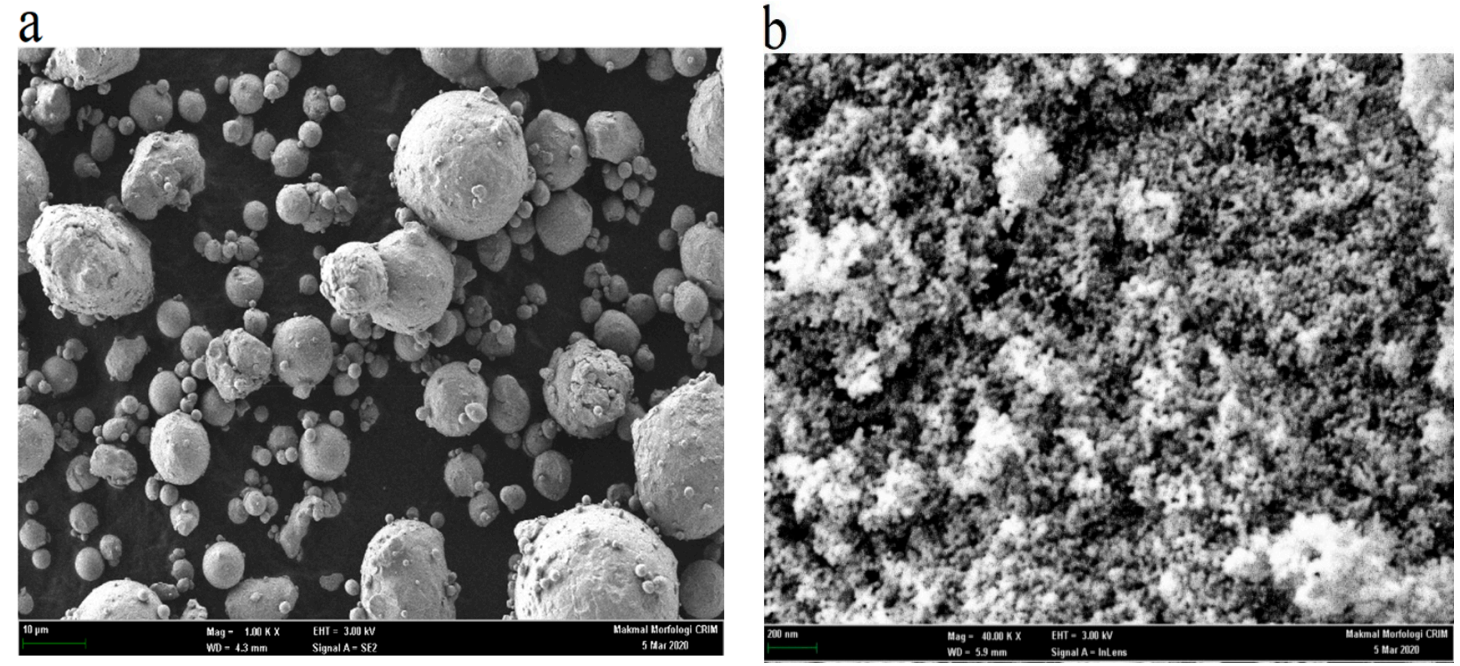

Figure 1. Field Emission Scanning Electron Microscopy (FESEM) micrographs of: (a) SS 17-4PH; and (b) 3YSZ powder.
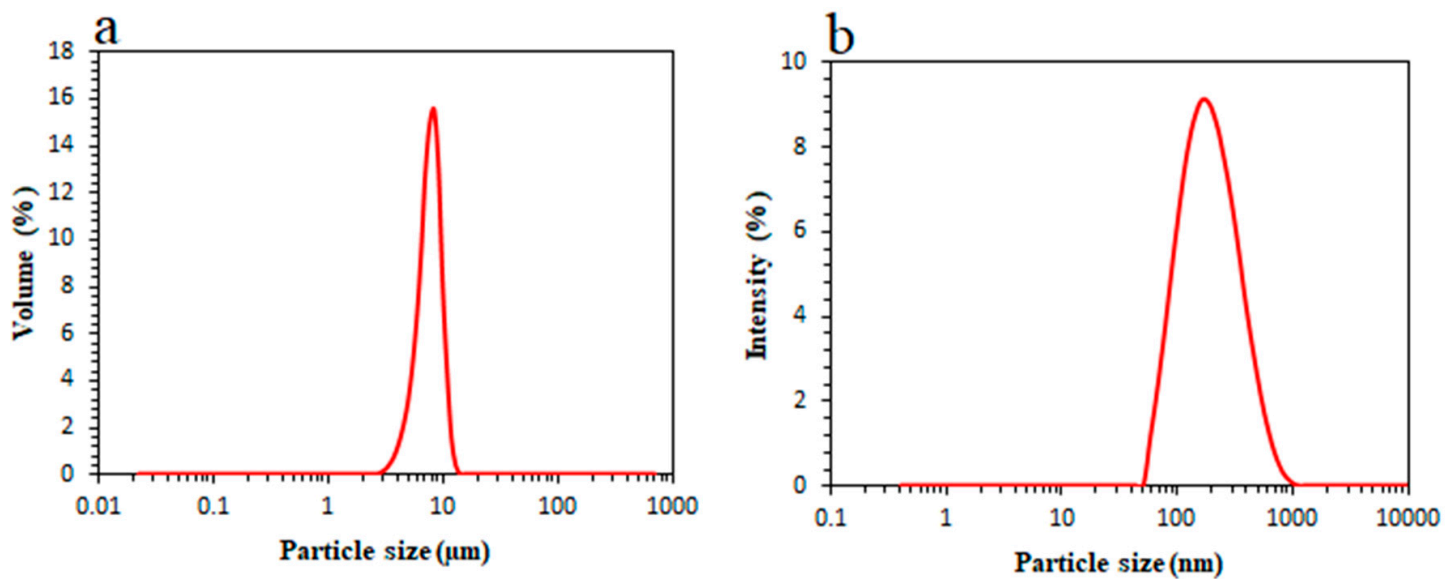

Figure 2. Particle size distribution of: (a) SS 17-4PH; and (b) 3YSZ powder.

Table 1. Characteristics of the PS and LDPE binders.

\begin{tabular}{cccccc}
\hline Binders & Supplier & Chemical Formula & Meting Point $\left({ }^{\circ} \mathrm{C}\right)$ & Density $\left(\mathrm{g} / \mathrm{cm}^{3}\right)$ & Content (wt.\%) \\
\hline PS & $\begin{array}{c}\text { Sime Darby Kempas Sdn. } \\
\text { Bhd., Malaysia }\end{array}$ & $\mathrm{CH}_{3}\left(\mathrm{CH}_{2}\right)_{14} \mathrm{COOH}$ & 63 & 0.891 & 60 \\
LDPE & $\begin{array}{c}\text { The Polyolefin Company } \\
\text { (Singapore) Pte Ltd. }\end{array}$ & $\left(\mathrm{C}_{2} \mathrm{H}_{4}\right) n$ & 117.3 & 0.91 & 40 \\
\hline
\end{tabular}

\subsection{Experimental Procedures}

\subsubsection{Mixing}

An oil absorption technique was employed during the experiment to determine the critical powder volume concentration (CPVC) value for both SS 17-4PH and 3YSZ materials [17]. The powder loadings of 2 and 3 vol.\% less than the CPVC were individually mixed with the binders at the ratio of $60 \mathrm{wt} . \%$ PS and 40 wt.\% LDPE in a roller blade-type W50 EHT Brabender mixer (Brabender GmbH \& Co. KG, Kulturstraße, Duisburg, Germany) at a mixing temperature of $150{ }^{\circ} \mathrm{C}$ and at a speed of $25 \mathrm{rpm}$ for $45 \mathrm{~min}$ to prepare the feedstocks. The dough-like mixture obtained from the mixing was then crushed into granules by utilizing a crusher machine. 


\subsubsection{Rheological Analysis}

A Shimadzu CFT-500D capillary rheometer (Shimadzu Corporation, Nakagyo-ku, Kyoto, Japan) with a diameter of $1 \mathrm{~mm}$ and $10 \mathrm{~mm}$ long die was used to analyze the rheological behaviors of SS 17-4PH and 3YSZ feedstocks with different powder loadings. Three different temperatures $(140,160$, and $180^{\circ} \mathrm{C}$ ) were implemented by the rheometer, and the Bagley correction was executed automatically by the capillary rheometer [18].

\subsubsection{Bi-Material Micro-Powder Injection Molding}

A DSM Xplore IM12 table-top injection molding machine (Xplore Instruments BV, Arendstraat, Sittard, Netherlands) was used to conduct the injection process. Based on the rheological measurements, injection molding trials were undertaken to fabricate the SS 17-4PH and 3YSZ micro-samples by manipulating the injection parameters, such as the injection temperature, pressure and time, mold temperature, and holding pressure. The similar injection parameters that demonstrated the suitability to fabricate both single material micro-parts (SS 17-4PH and 3YSZ) with the defect-free condition were also utilized to produce the bi-material micro-parts of SS 17-4PH and 3YSZ. The two-component micro-injection molded dumbbell shape and dimensions are shown in Figure 3.
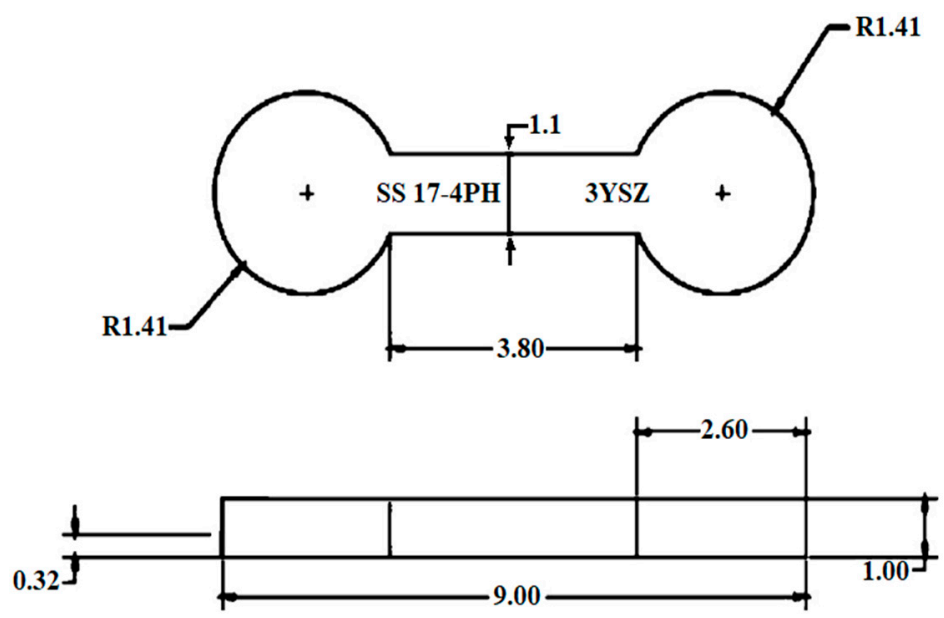

Figure 3. Dimensions of the bi-material micro-part of SS 17-4PH and 3YSZ.

\subsubsection{Solvent Debinding Process}

In determining the optimum solvent debinding temperature of the bi-material micro-part of SS $17-4 \mathrm{PH}$ and $3 \mathrm{YSZ}$, the single material micro-parts were first prepared and immersed in acetone for $40 \mathrm{~min}$ at five different temperatures of $30,40,50,60$, and $70^{\circ} \mathrm{C}$ to examine the debinding effect of each constituent of the two-component micro-part. Eventually, the bi-material micro-part was immersed in acetone at $70{ }^{\circ} \mathrm{C}$ for $40 \mathrm{~min}$. The removal rate of the PS binder through the solvent extraction process was then assessed by surveying the mass loss for five bi-material micro-samples under the same conditions.

\section{Results and Discussion}

\subsection{Optimal Powder Loading}

The powder loading is considered as an important factor as the success of the later stages of the injection molding process largely depends on it $[19,20]$. Fayyaz et al. [20] employed optimal powder content while conducting $\mu$ PIM of cemented tungsten carbide, which not only ensured low feedstock viscosity but also provided them with micro-parts having minimal defects and improved mechanical properties. Therefore, the optimal powder loading system was selected for this experiment. 
The optimal powder loading range typically depends on the critical powder volume concentration (CPVC). In this experiment, the CPVC of SS 17-4PH and 3YSZ powders were determined from the alteration of mixing torque, which was caused due to the incremental addition of oleic acid oil. It can be seen in Figure 4a,b that the addition of oil to the mixture had a marginal effect on raising the torque during the initial stage. The powder particle layer absorbed the oil, and with the stabilization of the mixing torque, the formation of clusters took place. The large increase of the torque was fostered by the extended clusters which continued to be unstable at the point of CPVC where the addition of oil with the mixture was carried out. Phenomena such as dilation of the solid structure and enhancement of the interparticle distance occurred when further liquid was added to the mixture [17,21]. The following equation was applied to calculate the percentage of CPVC at the highest torque value:

$$
\text { CPVC }(\%)=\frac{\text { Volume of powder }}{\text { Volume of powder }+ \text { Volume of oil }} \times 100
$$
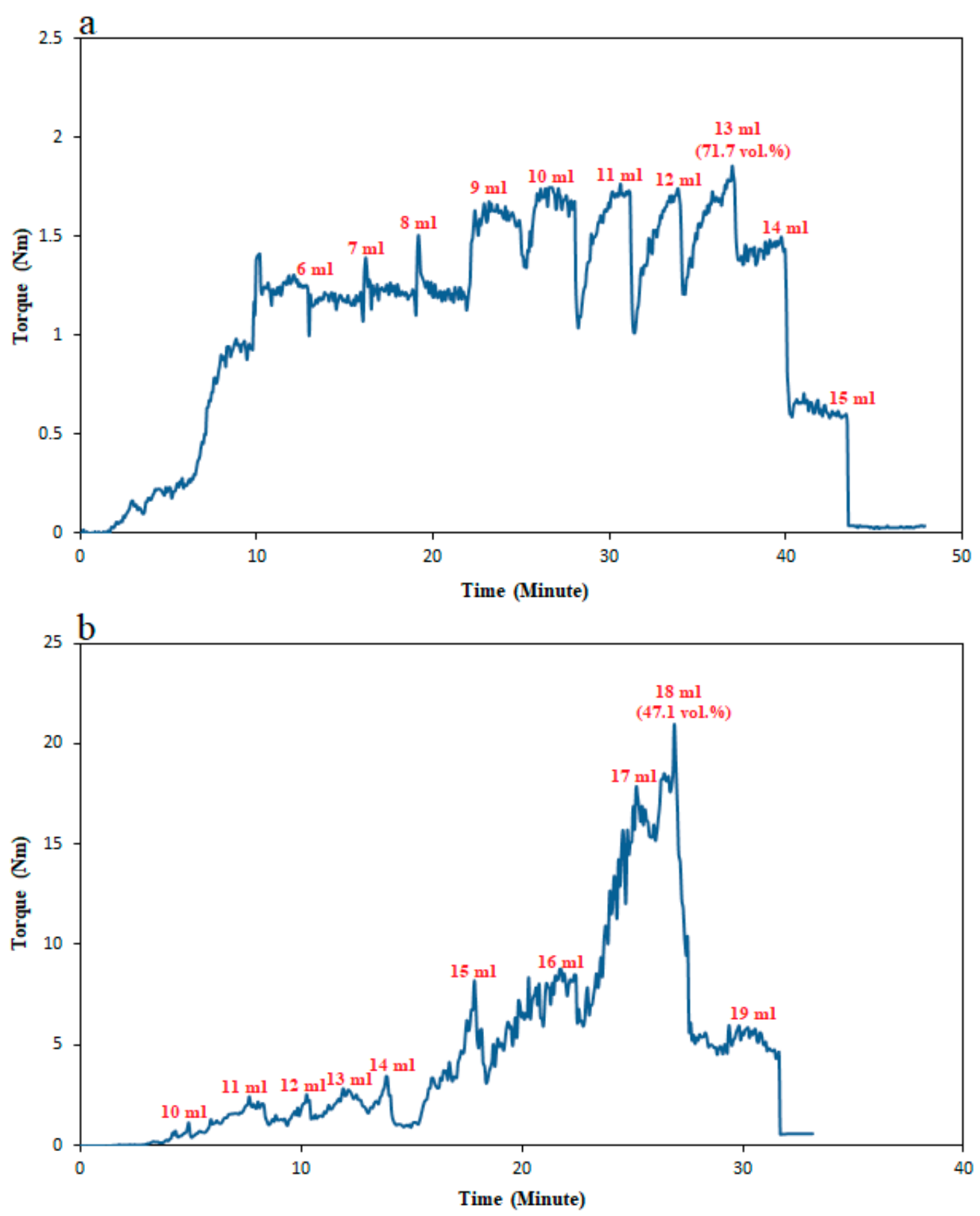

Figure 4. Evaluation of torque as a function of time for the powders (a) SS 17-4PH; and (b) 3YSZ. 
The CPVC of 17-4PH stainless steel and 3YSZ powders were 71.7 and 47.1 vol.\%, respectively. Emeka et al. [22] observed a close CPVC of 71 vol.\% for SS 17-4PH powder during their experiment. On the other hand, Foudzi et al. [23] measured the CPVC value of 45.26 vol.\% for nano-sized 3YSZ powder. Several factors may cause a difference in the CPVC value between the same type of power, which includes the material handling procedures, the measurement techniques, and the variation in the size of powder particles.

Usually, the power loading of $2-5$ vol.\% less than the critical value is considered as the optimal powder content [5]. In this experiment, the selected powder loadings for SS 17-4PH were 69 and 70 vol.\%. Li et al. [19], who conducted research on the effect of powder loading in the PIM process, claimed 68 vol.\% powder loading as optimal for 17-4PH stainless steel powder. Emeka et al. [22] employed SS 17-4PH with a powder loading of 68 vol.\% by applying a two-component powder injection molding (2C-PIM) process. Additionally, 44 and 45 vol.\% powder loadings were also selected for zirconia in this experiment to conduct further investigation in the later stages. According to German [24], the range of powder loading for ceramic is $50-55$ vol.\%. The powder loadings of submicronic zirconia selected for this experiment based on CPVC were far lower than the reported value of German [24]. Basically, the submicronic particles had a higher surface area, and, to cover each particle, a higher fraction of binder was required [25]. A powder loading of $45 \mathrm{vol} . \%$ was implemented by He et al. [26] during their experiment on PIM using nano-sized zirconia powder. Foudzi et al. [23] conducted research by using the $\mu$ PIM technique, where $37-43$ vol. $\%$ powder loading of nano zirconia powder was considered.

\subsection{Rheology}

The rheological analysis is considered as an important mechanism not only to prefigure the flow behavior of the feedstock but also to assess the filling of mold during the injection molding process [8]. In this experiment, the evaluation of the rheological properties was conducted in accordance with the viscosity profiling of the feedstock based on temperature against shear rate. Figure 5 displays the viscosity versus shear rate graph of $17-4 \mathrm{PH}$ stainless steel feedstocks at the temperatures of 140 , 160 , and $180^{\circ} \mathrm{C}$. It can be seen that the powder loadings of 69 and $70 \mathrm{vol} . \%$ had been taken into account for rheological measurements. Figure 5 demonstrates the reduction of feedstock viscosity with increasing shear rate, which is denoted as pseudoplastic behavior or shear thinning. Similar behavior was observed when a powder loading of $68 \mathrm{vol} . \%$ was considered for rheological analysis, as reported by Emeka et al. [7]. Essentially, pseudoplastic behavior not only secures the efficient filling of the mold cavity but also upgrades the effectiveness of the shape retention of the injection molded part [5]. Figure 5 shows that the range of viscosity for $69 \mathrm{vol}$ \% SS 17-4PH feedstock was 358.7-584.5 Pa.s at $140{ }^{\circ} \mathrm{C}$, which decreased to $174.4-437.9 \mathrm{~Pa} \cdot \mathrm{s}$ at $180^{\circ} \mathrm{C}$. By the same token, it can also be observed that the range of viscosity for SS 17-4PH feedstock with powder loading of $70 \mathrm{vol} . \%$ was $581-991 \mathrm{~Pa} \cdot \mathrm{s}$ at $140{ }^{\circ} \mathrm{C}$, which reduced to $218.7-790.9 \mathrm{~Pa} \cdot \mathrm{s}$ at the temperature of $180^{\circ} \mathrm{C}$. The reduction of attraction between the molecules of the binders with the raise of the temperature mainly drives this phenomenon [20]. It has been recommended by investigators that the viscosity level below $1000 \mathrm{~Pa} \cdot \mathrm{s}$ and the shear rate range $10^{2}-10^{5} \mathrm{~s}^{-1}$ ensure an effective flow of feedstock to the mold cavity $[27,28]$. In Figure 5 , SS 17-4PH feedstock with 70 vol. $\%$ powder loading exhibited $62-69.5 \%, 30.3-58.3 \%$, and $25.4-80.6 \%$ higher viscosity in comparison to feedstock with powder loading of $69 \mathrm{vol} . \%$ at the temperatures of 140 , 160 , and $180^{\circ} \mathrm{C}$, respectively. This can be attributed to the existence of more particles in higher powder loading, which resulted in increased fractions while the molten feedstock was extruded through the die of the capillary rheometer [23]. To fabricate micro-parts, an inevitable requirement is to keep the viscosity of feedstock as low as possible to fill the mold cavity competently. From this perspective, employing the powder loading of 69 vol. $\%$ for the later stages was preferable to 70 vol. $\%$. 


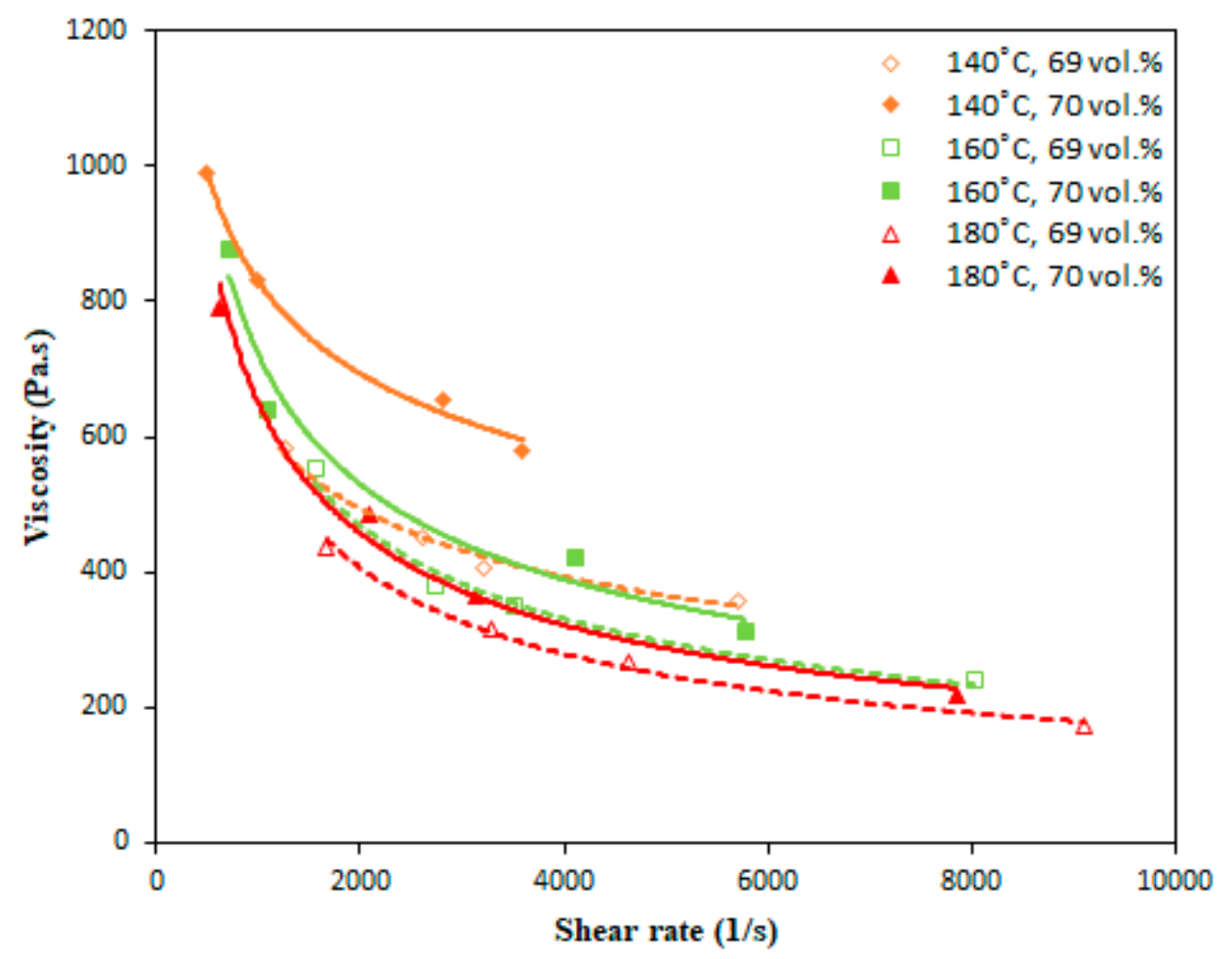

Figure 5. Relationship between the viscosity and shear rate of the SS 17-4PH feedstocks.

Similarly, the rheological behavior of 3YSZ feedstocks is illustrated in Figure 6. Similar to SS 17-4PH feedstocks, as shown in Figure 5, pseudoplastic behavior was also observed for 3YSZ feedstocks with two different powder loadings of 44 and 45 vol.\% (Figure 6). This result contradicts those of Foudzi et al. [23], who reported that dilatant flow or shear thickening was observed while rheological measurements were conducted on 3YSZ feedstocks with powder loading of 37-43 vol.\%. The segregation of powder and binder is related to dilatant behavior, where viscosity increases with increasing shear rate. In Figure 6, with the incremental temperature, the viscosity of the feedstocks decreased, but the viscosity range of $45 \mathrm{vol} \%$ powder loading at different temperatures was very high compared to 44 vol. $\%$ powder loading. The viscosity range obtained for $45 \mathrm{vol} . \%$ powder loading at the temperature of $140{ }^{\circ} \mathrm{C}$ was not recommendable as it showed viscosity higher than $1000 \mathrm{~Pa} \cdot \mathrm{s}$. Although the range of the viscosity of the feedstock at the temperature of 160 and $180{ }^{\circ} \mathrm{C}$ was close to the preferred viscosity value, it was still high enough to make the filling of molding cavity challenging during microfabrication. Therefore, using the $44 \mathrm{vol} . \%$ power loading for the further experiment was more feasible in comparison to $45 \mathrm{vol} . \%$.

In this experiment, the flow behavior index and the flow activation energy were evaluated to figure out the behaviors of the SS 17-4PH and 3YSZ feedstocks. As both the feedstocks displayed pseudoplastic behavior, the correlation between viscosity $(\eta)$ and shear rate $(\mathrm{Y})$ can be expressed by the equation given below:

$$
\eta=K Y^{n-1}
$$

where $n$ and $K$ are the flow behavior index and a constant, respectively. Basically, the shear sensitivity degree is indicated by $n$. The pseudoplastic and dilatant behaviors are displayed by the feedstocks when the value of $n$ is smaller and greater than 1, respectively. Based on Figures 5 and 6 , the calculated $n$ value for the different feedstocks of $17-4 \mathrm{PH}$ stainless steel and 3YSZ are presented in Table 2, which reveals that the value of $n$ decreased with increasing temperature for all feedstocks. The interaction between the powder particles and the molten binder influence the rheological properties of the feedstock experiencing shear. The mobility of the powder particles increases with the rising temperature, which eventually lower the value of the flow behavior index $[20,29,30]$. Table 2 also shows that the range of 
the flow behavior index for 69 vol.\% SS 17-4PH and 44 vol.\% $3 Y S Z$ are lower in comparison to 70 vol.\% SS 17-4PH and 45 vol.\% 3YSZ, respectively. This can be attributed to the higher binder fraction that increases the mobility of the powder particles at certain temperatures. The smaller is the value of $n$, the faster the viscosity changes with the shear rate.

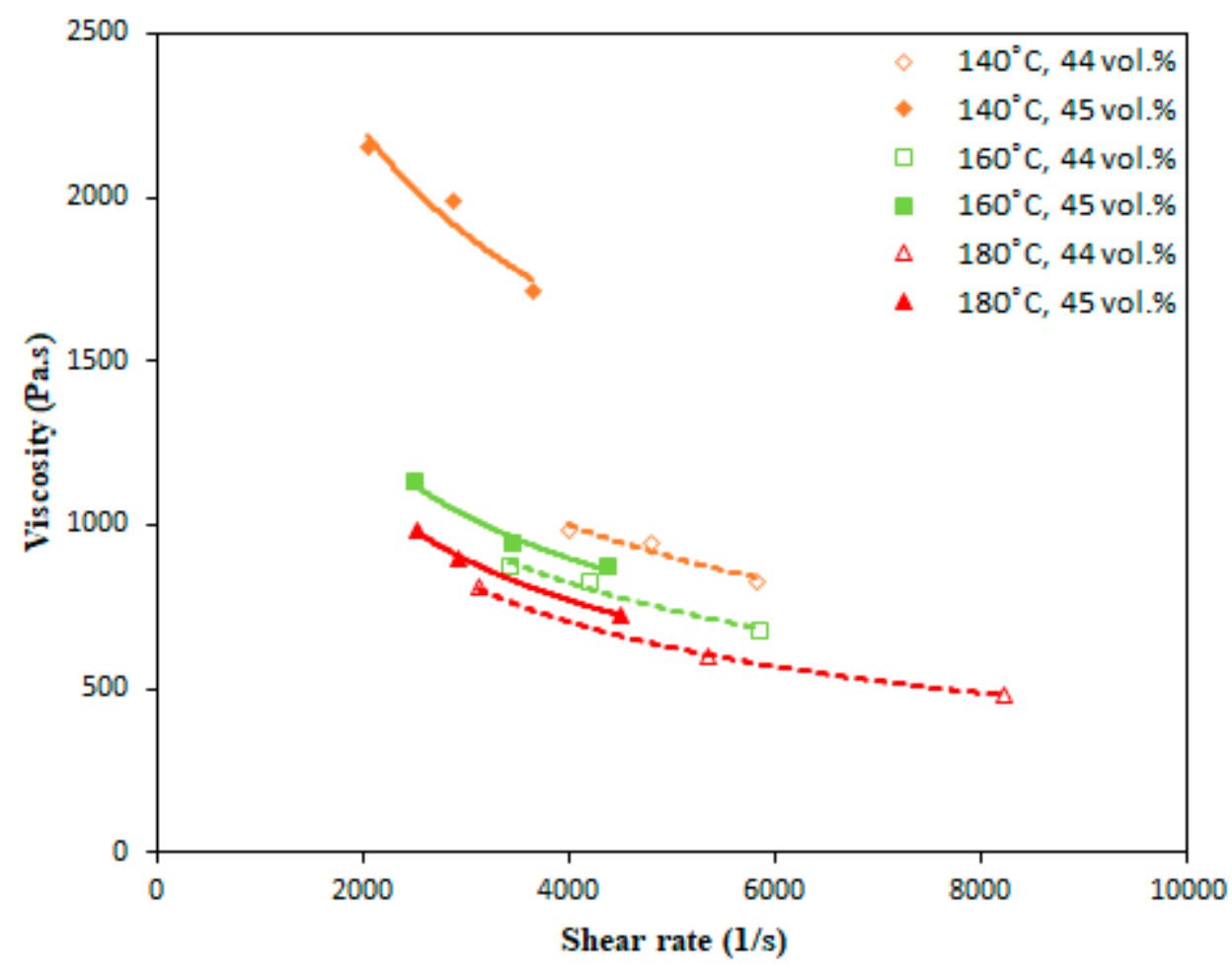

Figure 6. Relationship between the viscosity and shear rate of the 3YSZ feedstocks.

Table 2. Values of $n$ for SS 17-4PH and 3YSZ feedstocks at different temperatures.

\begin{tabular}{|c|c|c|c|}
\hline Feedstocks & Optimal Powder Loadings (vol.\%) & Temperature $\left({ }^{\circ} \mathrm{C}\right)$ & Flow Behavior Index ( $n)$ \\
\hline \multirow{6}{*}{ SS 17-4PH } & \multirow{3}{*}{69} & 140 & 0.672 \\
\hline & & 160 & 0.498 \\
\hline & & 180 & 0.457 \\
\hline & \multirow{3}{*}{70} & 140 & 0.742 \\
\hline & & 160 & 0.555 \\
\hline & & 180 & 0.492 \\
\hline \multirow{6}{*}{$3 Y S Z$} & \multirow{3}{*}{44} & 140 & 0.534 \\
\hline & & 160 & 0.514 \\
\hline & & 180 & 0.467 \\
\hline & \multirow{3}{*}{45} & 140 & 0.612 \\
\hline & & 160 & 0.528 \\
\hline & & 180 & 0.481 \\
\hline
\end{tabular}

Another important factor during the investigations of the rheological properties of a feedstock is the temperature dependency of viscosity, which can be obtained by calculating flow activation energy $(E)$ based on the Arrhenius equation given below:

$$
\eta(T)=\eta_{o} \exp (E / R T)
$$

where $\eta_{0}, R$, and $T$ are the viscosity at the reference temperature, gas constant, and temperature, respectively. In accordance with Equation (3), $E$ can be calculated from the slope of the graph of $\ln (\eta)$ versus $1 / T$. Based on Figure 7a, the value of $E$ for $17-4 \mathrm{PH}$ stainless steel feedstocks with two different 
power loadings of 69 and 70 vol.\% were 16.63 and $20.79 \mathrm{KJ} / \mathrm{mol}$, respectively. Similarly, as shown in Figure $7 \mathrm{~b}$, for 3 YSZ feedstocks with powder loadings of 44 and $45 \mathrm{vol} \%$, the values of $E$ were 16.63 and $33.26 \mathrm{KJ} / \mathrm{mol}$, respectively. In both cases, the higher values of $E$ were found with the increase of the powder loadings in the feedstocks. Basically, the higher sensitivity of the feedstock viscosity towards temperature is indicated by the higher value of $E$. Such scenario promotes a high probability of rapid solidification of the feedstock during the injection molding process [5,18]. A lower value of $E$ not only facilitates the flow of the feedstock to the mold before hardening but also minimizes the formation of defects during microfabrication [28,31].
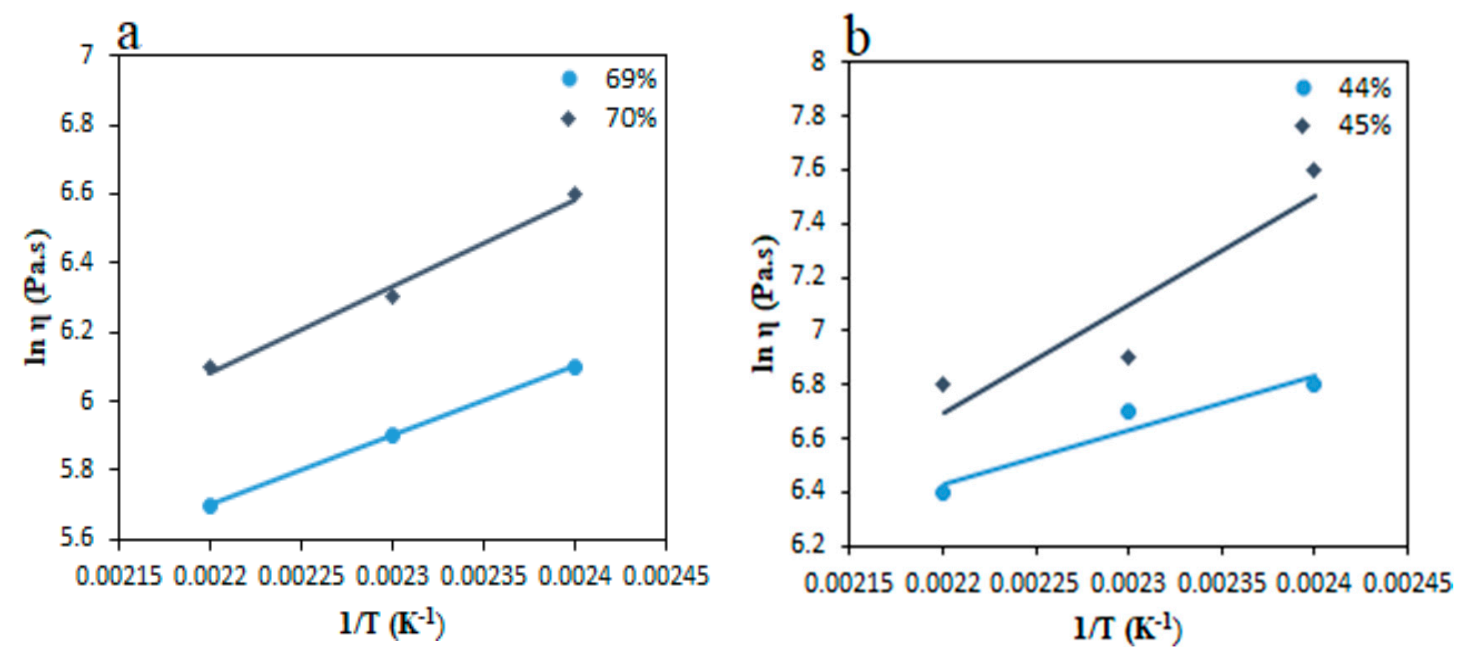

Figure 7. Correlation between viscosity and temperature for the feedstocks: (a) SS 17-4PH; and (b) 3 YSZ.

In conclusion, to fabricate the bi-material micro-parts of SS 17-4PH and 3YSZ, the rheological measurements of SS 17-4PH and 3YSZ feedstocks with different powder loadings were carried out. On the basis of the results, SS 17-4PH and 3YSZ feedstocks with powder loading of 69 and 44 vol.\%, respectively, displayed the best rheological properties in terms of low viscosity, high shear thinning and low activation energy. Consequently, these powder loadings were employed in subsequent stages.

\subsection{Injection Molding}

Based on rheological analysis, micro-injection molding trials were conducted on 17-4PH stainless steel and 3YSZ feedstocks with powder loading of 69 and 44 vol.\%, respectively. SS 17-4PH micro-parts with short shot defects were observed when mold temperatures lower than $45{ }^{\circ} \mathrm{C}$ were applied (Figure $8 \mathrm{a}-\mathrm{c}$ ). Similar defects were detected in the case of 3YSZ micro-parts, while mold temperatures lower than $65^{\circ} \mathrm{C}$ were used to fabricate parts (Figure 9a-c). These findings reveal that mold temperature plays an important role to fill the mold cavity. It is expected that, during micro-powder injection molding, SS 17-4PH and 3YSZ feedstocks become cold quickly since the dimensions of the mold cavity are small $[5,20]$. Concerning this, mold temperature of 45 and $65^{\circ} \mathrm{C}$ were employed during the fabrication of SS 17-4PH and 3YSZ micro-parts, respectively, to avoid short-shot defects (Figures 8d and 9d). The injection parameters applied to fabricate SS 17-4PH, and 3YSZ micro-parts are shown in Table 3.

As shown in Table 3, similar injection parameters were used to fabricate the micro-parts of SS 17-4PH and 3YSZ except for the mold temperatures. Here, higher mold temperature is required in the case of 3YSZ in comparison to SS 17-4PH. However, defect-free parts of SS 17-4PH were obtained when the mold temperature was increased from 45 to $65^{\circ} \mathrm{C}$, the same temperature used in $3 Y S Z$. Considering this result, the injection parameters of 3YSZ, as shown in Table 3, were employed to fabricate bi-materials micro-parts. The sequential mechanism was employed to fabricate the bi-materials micro-parts where 3YSZ feedstock was initially injected into the mold cavity. Then, the obtained micro-green-part of 3YSZ 
was cut in half and positioned into the mold cavity again. After that, SS 17-4PH feedstock was injected over the 3YSZ feedstock to bond together. After finishing the injection molding process, sufficient cooling of the mold was undertaken to avoid distortion of the bi-material green micro-parts during demolding. The two-component micro-injection molded part produced without any type of distortions such as even filling, jetting, and cracking is shown in Figure 10. There is no particular sequence that need to be followed to fabricate SS 17-4PH/3YSZ green micro-part. Defect-free bi-material micro-parts were also obtained when SS 17-4H feedstock was injected first, and, afterward, 3YSZ feedstock was injected. The FESEM micrograph of the green SS 17-4PH/3YSZ micro-part is presented in Figure 11. This illustrates that the SS 17-4PH and 3YSZ powder particles were well-dispersed in the matrices of the PS and LDPE binders. Furthermore, the interface of the interlocked green part consisting of SS 17-4PH and 3YSZ has also been revealed by the micrograph.

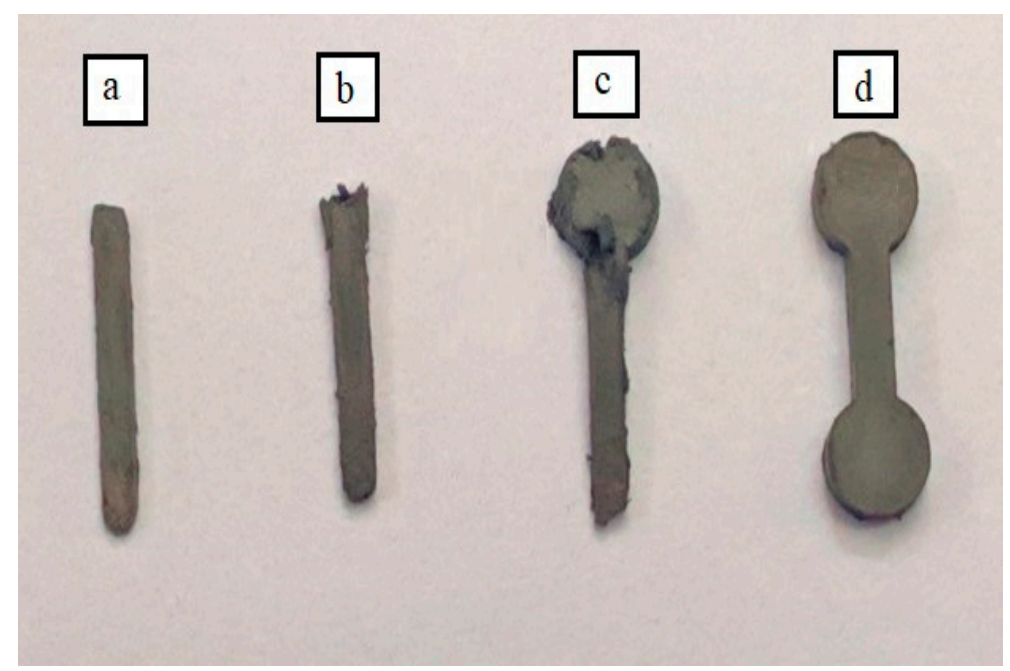

Figure 8. Injected micro-shaped SS 17-4PH parts at different mold temperatures: (a) $30{ }^{\circ} \mathrm{C}$; (b) $35^{\circ} \mathrm{C}$; (c) $40{ }^{\circ} \mathrm{C}$; and (d) $45^{\circ} \mathrm{C}$.

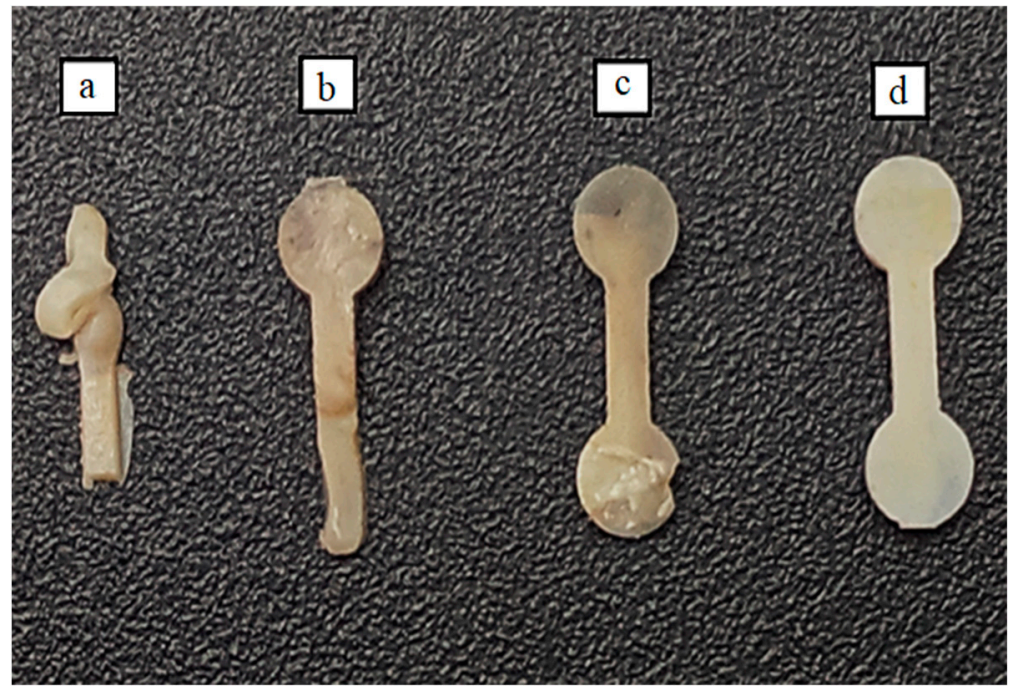

Figure 9. Injected micro-shaped $3 Y S Z$ parts at different mold temperatures: (a) $50{ }^{\circ} \mathrm{C}$; (b) $55{ }^{\circ} \mathrm{C}$; (c) $60^{\circ} \mathrm{C}$; and (d) $65^{\circ} \mathrm{C}$. 
Table 3. Injection molding parameters to produce SS 17-4PH and 3YSZ micro-parts.

\begin{tabular}{lll}
\hline Injection Parameters & \multicolumn{2}{c}{ Operating Process } \\
\hline & SS 17-4PH & 3YSZ \\
\hline Injection pressure & $10 \mathrm{bar}$ & $10 \mathrm{bar}$ \\
Compression pressure & $10 \mathrm{bar}$ & $10 \mathrm{bar}$ \\
Holding pressure & $10 \mathrm{bar}$ & $10 \mathrm{bar}$ \\
Melt temperature & $180^{\circ} \mathrm{C}$ & $180^{\circ} \mathrm{C}$ \\
Mold temperature & $45^{\circ} \mathrm{C}$ & $65^{\circ} \mathrm{C}$ \\
Injection time & $7 \mathrm{~s}$ & $7 \mathrm{~s}$ \\
Compression time & $7 \mathrm{~s}$ & $7 \mathrm{~s}$ \\
Holding time & $7 \mathrm{~s}$ & $7 \mathrm{~s}$ \\
\hline
\end{tabular}

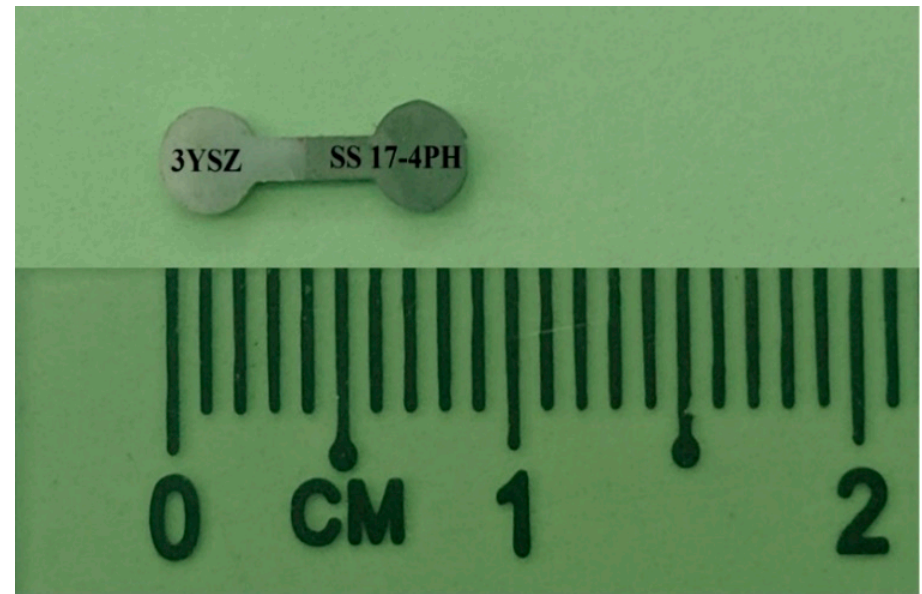

Figure 10. Bi-material micro-part of SS 17-4PH and 3YSZ materials.

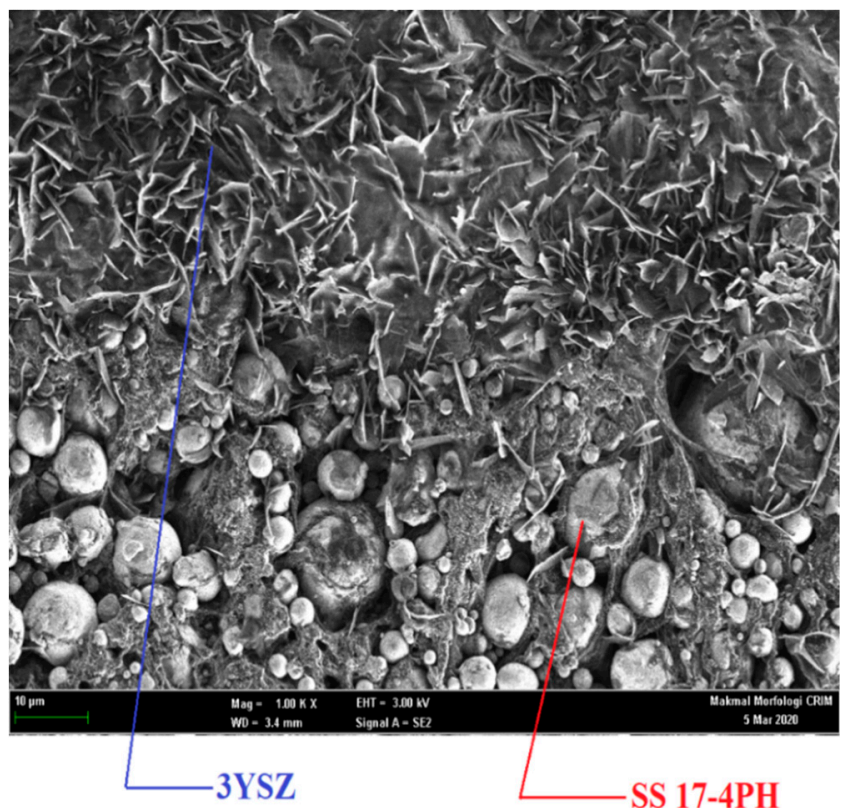

Figure 11. Bi-material micro-part of SS 17-4PH and 3YSZ materials.

\subsection{Solvent Debinding}

The binder system of this present study consisted of PS and LDPE. Debinding of the SS 17-4PH/3YSZ green micro-part was carried out in two stages. In the first instance, the injection molded part was immersed in the solvent bath to remove the soluble binder, categorized as a solvent debinding process. 
In the second place, the remaining soluble binder and the insoluble binders were removed from the part employing the thermal debinding process. Here, single material green micro-parts of SS 17-4PH and 3YSZ were immersed in acetone for $40 \mathrm{~min}$ to understand the solvent debinding behavior of each constituent part of the green bi-material micro-part. Figure 12a,b demonstrates the amount of soluble binder extraction with time for the SS 17-4PH and 3YSZ micro-samples, respectively, at the different temperatures of $30,40,50,60$, and $70{ }^{\circ} \mathrm{C}$. Both figures indicate that the mass loss of PS increased with the increase of both time and temperature. For each temperature, the removal rate of PS was shown to be very high during the first $20 \mathrm{~min}$, which then became slower or sometimes constant during the following $20 \mathrm{~min}$. In this experiment, the amount of binder extraction significantly increased from 51.6 to $89.3 \%$ for $17-4 \mathrm{PH}$ stainless steel, and 36.5 to $70.6 \%$ for $3 \mathrm{YSZ}$, when the temperature was increased from 30 to $70{ }^{\circ} \mathrm{C}$ with the immersion time of $40 \mathrm{~min}$ (Figure 12a,b). The solvent extraction process is regulated by the diffusion mechanism where the temperature is the most crucial parameter that influences the diffusion rate, and the higher binder removal occurs with the increase of the temperature as a consequence of greater diffusion rate [32]. No visible defects were detected in the SS 17-4PH and 3YSZ micro-samples when different solvent debinding temperatures were applied between 30 and $70{ }^{\circ} \mathrm{C}$. In the case of $17-4 \mathrm{PH}$ stainless steel, a huge crack was observed in the middle of the sample following $30 \mathrm{~min}$ of immersion at $80^{\circ} \mathrm{C}$, as shown in Figure 13. This can be attributed to the fast extraction rate of the binder and the softening of LDPE at such excessive temperature [33].
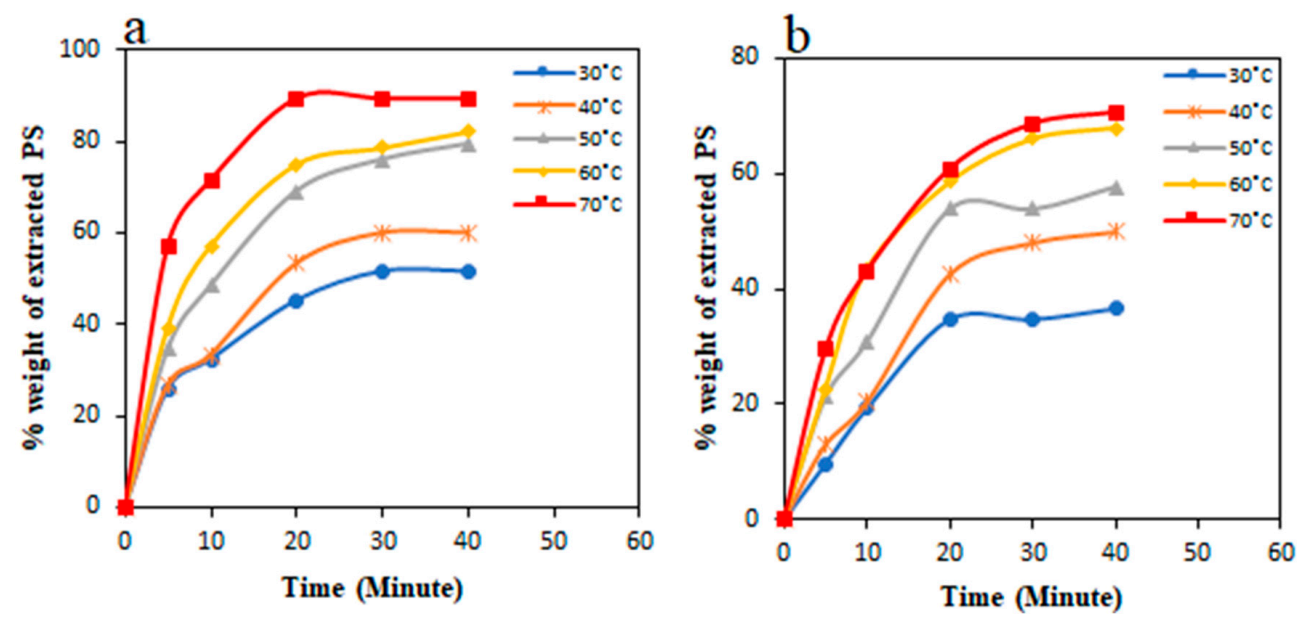

Figure 12. Mass loss of PS binder during solvent debinding from the micro-parts of (a) SS 17-4PH; and (b) 3 YSZ.

It can also be seen in Figure 12a,b that the binder extraction rate of these individual green parts is dissimilar. The 17-4PH stainless steel micro-part displayed the faster binder extraction rate in comparison to the 3YSZ micro-part having a particle size at the submicronic level. In addition, the submicronic powder particles were found to have higher surface areas which enhanced the inter-particle friction within the molecules of the injection molded component. Such phenomena could not only promote restrictions in flow but also slow down the debinding rate of 3YSZ micro-samples in comparison to $17-4 \mathrm{PH}$ stainless steel. The difference in the binder extraction rate between the SS 17-4PH and 3YSZ micro-samples signifies the potential for the thermal gradient to be induced at the bonding region of the SS 17-4PH/3YSZ bi-material micro-parts. Considering this phenomenon, longer binder extraction time and excessive temperature were not considered in this experiment to exterminate the chance of any types of cracks or defects occurring at the bonding zone [7]. 


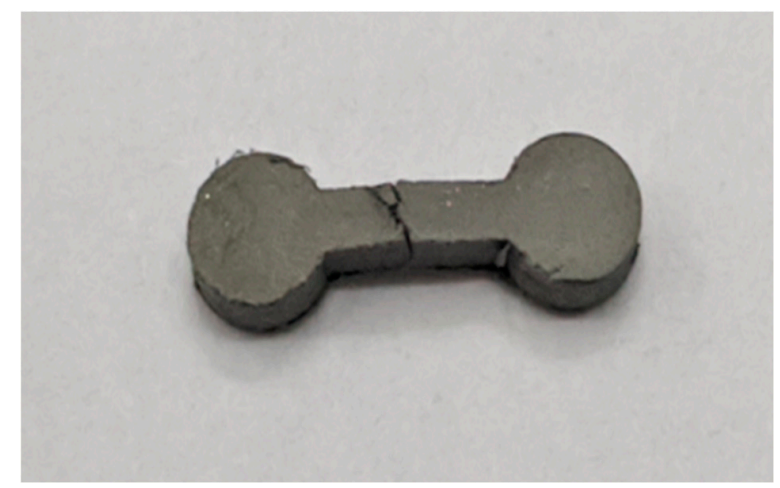

Figure 13. Cracking defect within SS 17-4PH micro-part during solvent extraction at $80^{\circ} \mathrm{C}$.

Since faster binder extraction occurred at $70{ }^{\circ} \mathrm{C}$ for the SS $17-4 \mathrm{PH}$ and $3 \mathrm{YSZ}$ micro-samples, a large crack occurred in the $17-4 \mathrm{PH}$ stainless steel specimen, which was solvent debound at $80^{\circ} \mathrm{C}$. The selected temperature for solvent debinding of bi-material micro-sample of SS 17-4PH and 3YSZ was $70^{\circ} \mathrm{C}$. The obtained debinding curve after immersing the two-material molded micro-part (SS $17-4 \mathrm{PH} / 3 \mathrm{YSZ}$ ) in acetone for $40 \mathrm{~min}$ at $70{ }^{\circ} \mathrm{C}$ is shown in Figure 14 . Based on this figure, most of the binder was removed after $20 \mathrm{~min}$, which was similar to those of the 17-4PH stainless steel and 3YSZ micro-parts, as shown in Figure 12a,b, respectively. Figure 14 shows that, for the bi-material micro-part, $73.3 \%$ of the binder was extracted after $40 \mathrm{~min}$ at $70{ }^{\circ} \mathrm{C}$, which was lower than $89.3 \%$ for the single material micro-part of $17-4 \mathrm{PH}$ stainless steel, but slightly higher than $70.6 \%$ for the $3 \mathrm{YSZ}$ micro-part, as shown in Figure 12a,b, respectively. From visual observation, no cracks or defects were evident in the SS 17-4PH/3YSZ micro-component, especially at the bonding area as the PS cannot be removed entirely as it provides capillary paths and holes to eliminate the leftover binders in the thermal debinding stage. Figure 15 shows the FESEM images of the single-material and bi-material micro-samples that were solvent debound at $70{ }^{\circ} \mathrm{C}$ while the debinding time was $40 \mathrm{~min}$. As shown in Figure 15a-c, most of the PS binder was eliminated from SS 17-4PH, 3YSZ, and SS 17-4PH/3YSZ micro-parts, leaving an adequate open-pore structure. Such structure is required to avoid cracking during the thermal debinding process.

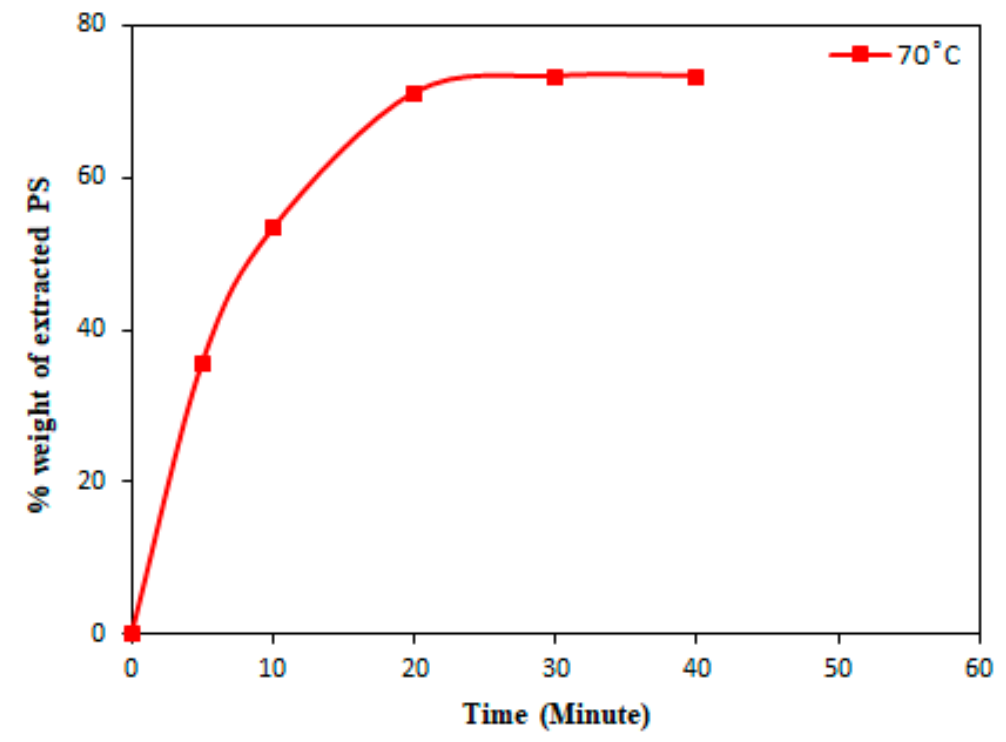

Figure 14. Mass loss of PS binder from SS 17-4PH/3YSZ micro-part at optimal solvent debinding temperature. 

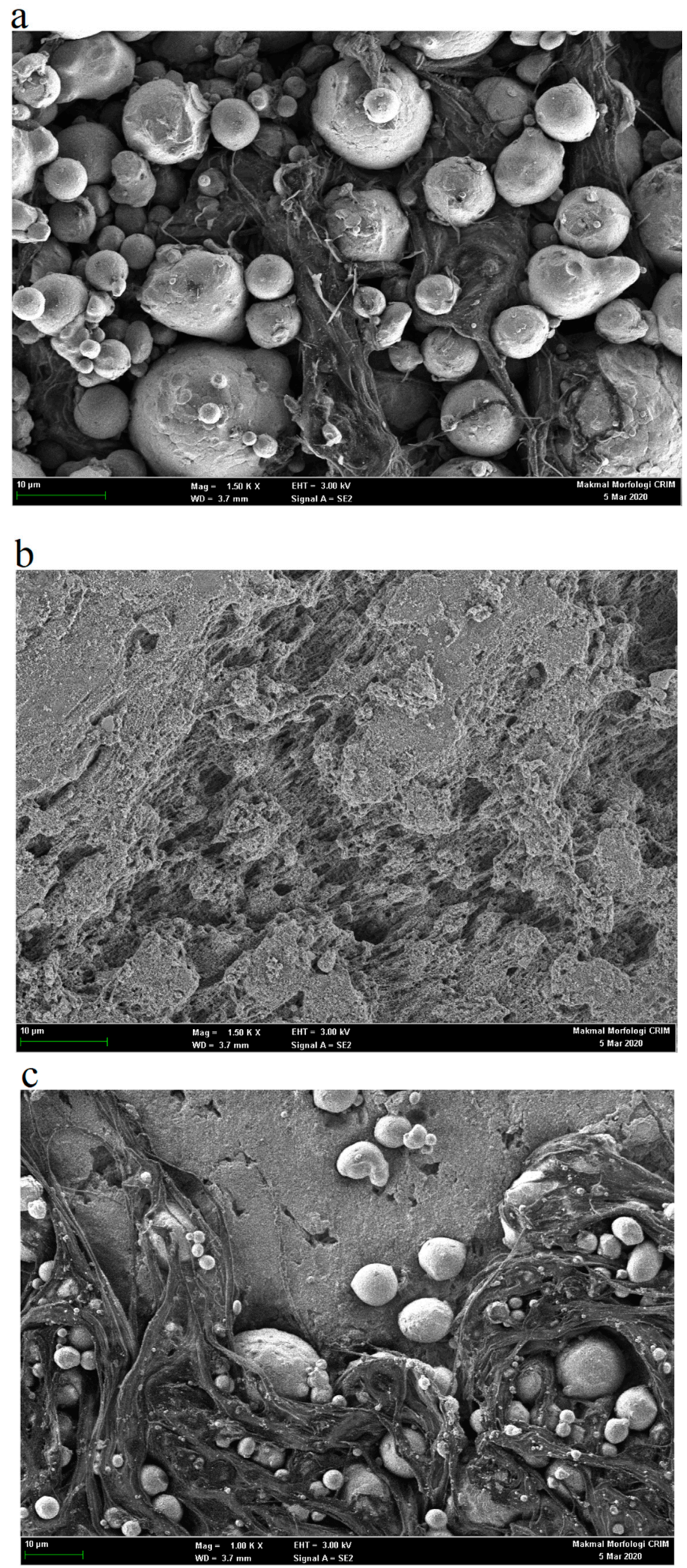

Figure 15. FESEM images of the samples solvent debound at $70{ }^{\circ} \mathrm{C}$ after $40 \mathrm{~min}$ of immersion: (a) SS 17-4PH micro-part; (b) 3YSZ micro-part; and (c) SS 17-4PH/3YSZ bi-material micro-part. 


\section{Conclusions}

The feasibility of using SS 17-4PH and submicronic 3YSZ powder to prepare bi-material green micro-parts and their solvent debinding behavior were investigated in this study. Based on the CPVC, the optimal powder loadings that were selected; 69 and 70 vol.\% for SS 17-4PH and 44 and 45 vol.\% for 3YSZ were considered for rheological measurements. The findings of the study are outlined below:

- Pseudoplastic behavior was observed for all feedstocks of SS 17-4PH and 3YSZ prepared using the optimal powder loadings. Moreover, the viscosity of each feedstock reduced with increasing temperature. Concerning low viscosity, high shear thinning, and low activation energy, the best rheological properties were demonstrated by the SS 17-4PH and 3YSZ feedstocks with the powder loadings of 69 and $44 \mathrm{vol} . \%$, respectively, which were used in the later stages of the study.

- A sequential mechanism was utilized to produce bi-material micro-parts of SS $17-4 \mathrm{PH}$ and 3YSZ. The success of the injection molding process was influenced by a significant parameter named as the "mold temperature". Defects in the samples of SS 17-4PH and 3YSZ were detected when mold temperatures less than 45 and $65{ }^{\circ} \mathrm{C}$ were applied, respectively. The implementation of a mold temperature of $65{ }^{\circ} \mathrm{C}$ during the entire injection molding process ensured defect-free green bi-material micro-parts.

- Based on the solvent debinding behavior of the individual green micro-parts of SS 17-4PH and 3YSZ, the green bi-material micro-part was solvent debound at $70{ }^{\circ} \mathrm{C}$. Around $73.3 \%$ PS was removed following $40 \mathrm{~min}$ of immersion in acetone where most of the binder was eliminated within the initial $20 \mathrm{~min}$. Moreover, a defect-free part ensured the successful accomplishment of the solvent debinding process.

Author Contributions: Conceptualization, methodology, formal analysis, and investigation, A.B. and A.B.S.; writing—original draft preparation, A.B.; writing—review and editing, A.B., A.B.S., N.H.J., and N.M.; supervision, A.B.S.; and funding acquisition, A.B.S. and N.M. All authors have read and agreed to the published version of the manuscript.

Funding: This research was funded by [Universiti Kebangsaan Malaysia] grant number [DIP-2019-009 and DIP-2017-001] and [Ministry of Higher Education Malaysia] grant number [FRGS/1/2017/TK03/UKM/02/1].

Acknowledgments: The authors would like to thank [Universiti Kebangsaan Malaysia] grant number [DIP-2019-009 and DIP-2017-001] and [Ministry of Higher Education Malaysia] grant number [FRGS/1/2017/TK03/UKM/02/1] for their financial support.

Conflicts of Interest: The authors declare no conflict of interest.

\section{References}

1. Imgrund, P.; Rota, A.; Wiegmann, M. Getting better bonding at tiny interfaces. Met. Powder Rep. 2007, 62, 31-34. [CrossRef]

2. Ruh, A.; Piotter, V.; Plewa, K.; Ritzhaupt-Kleissl, H.-J.; Hausselt, J. Development of two-component micropowder injection molding (2C-MicroPIM)—process development. Int. J. Appl. Ceram. Technol. 2011, 8, 610-616. [CrossRef]

3. Checot-Moinard, D.; Rigollet, C.; Lourdin, P. Powder injection moulding PIM of feedstock based on hydrosoluble binder and submicronic powder to manufacture parts having micro-details. Powder Technol. 2011, 208, 472-479. [CrossRef]

4. Escobar, C.F.; Santos, L.A.D. New eco-friendly binder based on natural rubber for ceramic injection molding process. J. Eur. Ceram. Soc. 2015, 35, 3567-3575. [CrossRef]

5. German, R.M.; Bose, A. Injection Molding of Metals and Ceramics; Metal Powder Industries Federation: Princeton, NJ, USA, 1997.

6. Lin, D.; Sanetrnik, D.; Cho, H.; Chung, S.T.; Kwon, Y.S.; Kate, K.H.; Hausnerova, B.; Atre, S.V.; Park, S.J. Rheological and thermal debinding properties of blended elemental Ti-6Al-4V powder injection molding feedstock. Powder Technol. 2017, 311, 357-363. [CrossRef] 
7. Emeka, U.B.; Sulong, A.B.; Muhamad, N.; Sajuri, Z. Solvent de-binding of Bi-material green component of two-component powder injection moulded stainless steel and zirconia. Int. J. Mech. Mechatron. Eng. 2018, 18, 96-104.

8. Ramli, M.I.; Sulong, A.B.; Muhamad, N.; Muchtar, A.; Zakaria, M.Y. Effect of sintering on the microstructure and mechanical properties of alloy titanium-wollastonite composite fabricated by powder injection moulding process. Ceram. Int. 2019, 45, 11648-11653. [CrossRef]

9. Emeka, U.B.; Sulong, A.B.; Muhamad, N.; Sajuri, Z.; Salleh, F. Two component injection molding of bi-material of stainless steel and yttria-stabilized zirconia - green part. J. Kejuruteraan 2017, 29, 49-55. [CrossRef]

10. Tseng, W.J.; Hsu, C.-K. Cracking defect and porosity evolution during thermal debinding in ceramic injection moldings. Ceram. Int. 1999, 25, 461-466. [CrossRef]

11. Raza, M.R.; Ahmad, F.; Omar, M.A.; German, R.M. Effects of cooling rate on mechanical properties and corrosion resistance of vacuum sintered powder injection molded 316L stainless steel. J. Mater. Process. Technol. 2012, 212, 164-170. [CrossRef]

12. Choi, S.-H.; Kang, S.-D.; Kwon, Y.S.; Lim, S.G.; Cho, K.K.; Ahn, I.-S. The effect of sintering conditions on the properties of WC-10wt\% Co PIM compacts. Res. Chem. Intermed. 2010, 36, 743-748. [CrossRef]

13. Rajabi, J.; Zakaria, H.; Muhamad, N.; Sulong, A.B.; Fayyaz, A. Fabrication of miniature parts using nano-sized powders and an environmentally friendly binder through micro powder injection molding. Microsyst. Technol. 2015, 21, 1131-1136. [CrossRef]

14. Torralba, J.M.; Hidalgo, J.; Jiménez-Morales, A. Powder injection moulding: Processing of small parts of complex shape. Int. J. Microstruct. Mater. Prop. 2013, 8, 87-96. [CrossRef]

15. Aggarwal, G.; Smid, I.; Park, S.J.; German, R.M. Development of niobium powder injection molding. Part II: Debinding and sintering. Int. J. Refract. Met. Hard Mater. 2007, 25, 226-236. [CrossRef]

16. Quinard, C.; Barriere, T.; Gelin, J.C. Development and property identification of 316L stainless steel feedstock for PIM and $\mu$ PIM. Powder Technol. 2009, 190, 123-128. [CrossRef]

17. Fayyaz, A.; Muhamad, N.; Sulong, A.B.; Yunn, H.S.; Amin, S.Y.M.; Rajabi, J. Micro-powder injection molding of cemented tungsten carbide: Feedstock preparation and properties. Ceram. Int. 2015, 41, 3605-3612. [CrossRef]

18. Thavanayagam, G.; Pickering, K.L.; Swan, J.E.; Cao, P. Analysis of rheological behaviour of titanium feedstocks formulated with a water-soluble binder system for powder injection moulding. Powder Technol. 2015, 269, 227-232. [CrossRef]

19. Li, Y.; Li, L.; Khalil, K.A. Effect of powder loading on metal injection molding stainless steels. J. Mater. Process. Technol. 2007, 183, 432-439. [CrossRef]

20. Fayyaz, A.; Muhamad, N.; Sulong, A.B.; Rajabi, J.; Wong, Y.N. Fabrication of cemented tungsten carbide components by micro-powder injection moulding. J. Mater. Process. Technol. 2014, 214, 1436-1444. [CrossRef]

21. Reddy, J.J.; Vijayakumar, M.; Tallapragada, R.M.R.; Ramakrishnan, P. Loading of solids in a liquid medium: Determination of CBVC by torque rheometry. J. Eur. Ceram. Soc. 1996, 16, 567-574. [CrossRef]

22. Emeka, U.B.; Sulong, A.B.; Muhamad, N.; Sajuri, Z. The characterization and rheological investigation of materials for powder injection moulding. J. Mech. Eng. 2017, 3, 97-107.

23. Foudzi, F.M.; Muhamad, N.; Sulong, A.B.; Zakaria, H. Yttria stabilized zirconia formed by micro ceramic injection molding: Rheological properties and debinding effects on the sintered part. Ceram. Int. 2013, 39, 2665-2674. [CrossRef]

24. German, R.M. Sintering Theory and Practice; Wiley: New York, NY, USA, 1996.

25. Luo, J.-S.; Yi, Z.-Z.; Xiao, B.; Gao, Y.; Xie, Z.-P.; Li, J.-B.; Huang, Y. Injection molding of ultra-fine zirconia (Y-TZP) powders. J. Ceram. Process. Res. 2006, 7, 14-19.

26. He, J.; Shao, Z.; Khan, D.F.; Yin, H.; Elder, S.; Zheng, Q.; Qu, X. Investigation of inhomogeneity in powder injection molding of nano zirconia. Powder Technol. 2018, 328, 207-214. [CrossRef]

27. Jabir, S.M.; Noorsyakirah, A.; Afian, O.M.; Nurazilah, M.Z.; Aswad, M.A.; Afiq, N.H.M.; Mazlan, M. Analysis of the rheological behavior of copper metal injection molding (MIM) feedstock. Procedia Chem. 2016, 19, 148-152. [CrossRef]

28. Choi, J.-P.; Park, J.-S.; Hong, E.-J.; Lee, W.-S.; Lee, J.-S. Analysis of the rheological behavior of Fe trimodal micro-nano powder feedstock in micro powder injection molding. Powder Technol. 2017, 319, $253-260$. [CrossRef] 
29. Yang, W.-W.; Yang, K.-Y.; Hon, M.-H. Effects of PEG molecular weights on rheological behavior of alumina injection molding feedstocks. Mater. Chem. Phys. 2003, 78, 416-424. [CrossRef]

30. Loebbecke, B.; Knitter, R.; Haußelt, J. Rheological properties of alumina feedstocks for the low-pressure injection moulding process. J. Eur. Ceram. Soc. 2009, 29, 1595-1602. [CrossRef]

31. Huang, B.; Liang, S.; Qu, X. The rheology of metal injection molding. J. Mater. Process. Technol. 2003, 137, 132-137. [CrossRef]

32. Heng, S.Y.; Raza, M.R.; Muhamad, N.; Sulong, A.B.; Fayyaz, A. Micro-powder injection molding ( $\mu$ PIM) of tungsten carbide. Int. J. Refract. Met. Hard Mater. 2014, 45, 189-195. [CrossRef]

33. Ani, S.M.; Muchtar, A.; Muhamad, N.; Ghani, J.A. Fabrication of zirconia-toughened alumina parts by powder injection molding process: Optimized processing parameters. Ceram. Int. 2014, 40, 273-280. [CrossRef]

(C) 2020 by the authors. Licensee MDPI, Basel, Switzerland. This article is an open access article distributed under the terms and conditions of the Creative Commons Attribution (CC BY) license (http://creativecommons.org/licenses/by/4.0/). 